
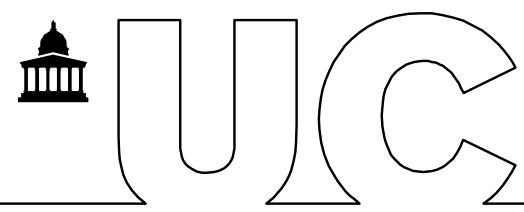

Zlotowitz, S; Barker, C; Moloney, O; Howard, C; (2015) Service users as the key to service change? The development of an innovative intervention for excluded young people. Child and Adolescent Mental Health (In press). Downloaded from UCL Discovery: http://discovery.ucl.ac.uk/ 1470824

\title{
ARTICLE
}

\section{Service users as the key to service change? The development of an innovative intervention for excluded young people}

\author{
Dr. Sally Zlotowitz ${ }^{1}$, Professor Chris Barker ${ }^{2}$, Dr. Olive Moloney and Dr. Charlotte Howard ${ }^{1}$, \\ ${ }^{1}$ MAC-UK, London, ${ }^{2}$ University College London
}

\section{Abstract}

Background

Excluded young people, especially those affected by street gangs, often have complex unmet needs and high levels of health and social inequalities. This paper outlines the development of Music \& Change, an innovative and comprehensive intervention accessible to young people, which aimed to holistically meet the mental health and other needs of its participants and ultimately to reduce offending rates. Its central principle was co-production and partnership with its potential users.

Method

The setting was an inner-city housing estate; the core group of participants was 15 young people aged 16-22. The intervention used contemporary music skills (e.g. DJing and lyric writing) and other co-produced project activities as a vehicle to build relationships with practitioners and address young people's multiple needs. Data was gathered using a focused ethnography, largely from field notes, and analysed using thematic analysis in order to ascertain users' perceptions of its delivery.

Results

Young people identified six key principles of the intervention, such as the need for, consistent relationships with trusted staff, mental health support to be wrapped round other youth-led activities and local service delivery within their safe territories.

Discussion

Music \& Change was valued by young people who do not easily engage with professionals and services. The findings led to the development of the 'Integrate' model, which is using these co-produced principles to underpin several new pilot projects that aim to address the health and social inequalities of excluded young people.

Keywords: young offenders, co-production, intervention, mental health, gangs. 


\section{Key Practitioner Messages}

- Excluded young people involved in gangs and those at risk of offending have high levels of unmet mental health needs, alongside other complex needs.

- Substantial service innovation may be required to engage excluded young people.

- Practitioners can work in partnership with peer groups of young people to co-produce youth-led activities and interventions that generate long term relationships, and allow for more flexible therapeutic input and 'wraparound' support, such as 'street therapy.'

- Street therapy approaches aim to support young people with a range of needs, including social, economic, emotional and occupational, and are consistent with promising mentalization-based and keyworking approaches.

- Developing services that can generate wider contextual change is important to young people and their integration.

\section{Introduction}

UK and international policy have recently started to emphasize that youth violence and gang membership are crucial public health issues that reach beyond the criminal justice system (Berelowitz, 2011; Catch 22 and MHP Health, 2013; Department of Health, 2009; Home Office, 2011; North West Public Health Observatory, 2012). These policy approaches stress the need for effective early intervention delivered in ways that engage affected young people.

Young people involved in or affected by street gangs ${ }^{1}$ have multiple, complex and largely unmet needs. These needs relate to mental health, social care, employment, social support, access to community resources and emancipation from the structural conditions relating to poverty, inequality, societal exclusion and discrimination. They are associated with poorer long-term outcomes on a range of key indicators compared to similar peers (Coid et al., 2013; Gilman, Hill \& Hawkins, 2014; Goldson \& Jamieson, 2002; Kelly, 2010; Khan et al., 2013; Pitts, 2008).

Local authorities and third sector organisations provide the majority of interventions for young people affected by gangs in the UK. Provision is piecemeal and inconsistent as each local authority has different resources to tackle the issue, and the evidence base for these routine, real world interventions remains weak (Catch 22 and MHP Health, 2013; Densley, 2011; McMahon, 2013). Overall, multi-agency and multi-component interventions that address comprehensive needs seem most promising (Hodgkinson et al., 2009; McMahon, 2013). However, explicit mental health components are usually missing from these interventions, which are often enforcement-led and from a US context (e.g. Braga et al., 2001).

Despite such elevated needs, there is a substantial gap between the mental health and support services offered in the community by statutory services in the UK and their take-up by these traditionally 'hard to reach' young people (Barrett et al., 2006; Chitsabesan et al., 2006; Kurtz, Thornes, \& Bailey, 1998; Walsh et al., 2011; Youth Justice Board, 2005). These limitations may be partly explained by the use of a conventional approach to mental health provision, in which a young person is referred for an appointment to meet an unfamiliar and

\footnotetext{
${ }^{1}$ For the purposes of this article and the intervention street gangs are defined in accordance with the Centre for Social Justice report (2009). We are aware of the use of the term 'gang' being contentious so we refer to excluded young people where we can (Hallsworth \& Young, 2008).
} 
unchosen therapist, often in a clinic setting and after a crisis has already happened. This approach is likely to create multiple barriers for excluded young people so that services become 'hard-to-reach', from geographical barriers, such as neighbourhood territories, to psychological barriers, such as distrust of professionals (Flanagan \& Hancock, 2010; Lemma, 2010; Kintrea, Banister, Reid \& Suzuki, 2008; Oetzel \& Scherer, 2003). When young people do attend, psychological interventions for young offenders are short term, and the evidence base for these interventions for young people involved in gangs is inconclusive (Fisher, Montgomery \& Gardner, 2008). Multi-systemic therapy, the recommended intervention in the NICE (2013) guidelines for young people with a Conduct Disorder diagnosis in the UK, shows less positive outcomes for young people associated with negative peer groups (Boxer, 2011).

The present paper describes the development of the Music \& Change (M\&C) project, an innovative, complex intervention co-designed to fill the gap for this excluded group. The project and its approach arose from two years of working in close partnership with young people. It was 'bottom-up' rather than 'top-down', in that its development was based on the central principles of co-production and asset-based approaches (Foot \& Hopkins, 2010). This paper therefore aims to detail the development of a co-produced intervention that had little pre-determined content, structure and processes.

In terms of the MRC framework (Campbell et al., 2007; Craig et al., 2008), this piece of work can be conceptualised as a pre-pilot feasibility study. MRC guidance stipulates that new interventions have a clear theoretical rationale. The theoretical conceptualisation of young people's mental health and gang-related activity was underpinned by a systemic framework of personal, relational and collective levels (Evans \& Prilleltensky, 2007). Causal factors are multiple and complex across these levels: evidence-based risk and protective factors relate to personal psychological attributes (e.g. impulsivity, relational influences (e.g. anti-social peer group, domestic violence), collective-level influences (e.g. exclusion and underresourced communities). This framework informed our clinical formulations (for example, see an integrated model of gang involvement developed by Wood and Alleyne, 2010) and also the approach. For instance, the approach became underpinned by community psychology theory and practice, in which practitioners join alongside excluded or oppressed communities to design projects and services in partnership. These co-produced projects draw on the communities' resiliencies and assets to create change for, and also beyond, the individual. The aim becomes to transform wider systemic factors, for example at the relational and collective levels as well (Evans \& Prilleltensky, 2007).

Co-production with communities is recommended in NICE (2008) guidelines for community engagement in public health interventions and may lead to more effective interventions for this group (Hodkginson et al., 2009; Pitts, 2004). Excluded young people are experts by their experience and bring essential and unique knowledge, resources and assets which can be drawn upon to create change for individuals and communities (Foot \& Hopkins, 2010; Slay \& Stephens, 2013). This type of service-user involvement is recommended by research guidelines for the development of complex interventions (e.g., Craig et al., 2008).

We hypothesized that our intervention would reduce social exclusion and increase wellbeing by giving young people a positive experience of receiving help themselves and also a sense of self efficacy from contributing to designing their own programme, by helping their 
peers and increasing participation (Jason \& Rhodes, 1989; Quigley, 2004). In addition, we theorised that the intervention would offer opportunities for young people to gain experience, utilise their expertise, practice skills and strengths to help others in a context where practitioners could scaffold, role model and providing psychoeducation, important processes in prevention programmes (Weissberg, Kumpfer \& Seligman, 2003).

Attachment and mentalization-based theory informed our understanding of excluded young people's help-seeking behaviours, relational behaviours and personal level formulations of their mental health (see Bevington \& Fuggle, 2012). Thus the intervention was informed by a relational focus to service delivery, in which there is a focus on the building of a trusted relationship between a keyworker and a young person by drawing on mentalization-based theory and practice.

The data presented derives from a focused ethnography (Savage 2006; Simonds, Camic \& Causey, 2012), conducted as a formative evaluation to understand key components for further refinement and piloting. As readers will appreciate, this target population of ganginvolved young people presents challenges to conducting systematic research, in terms of their motivation to complete formal research measures when they have not actively sought a referral to a service. The study population was also fluid as young people were not asked to make a firm commitment to participate. An ethnographic approach was able to accommodate the needs of the group whilst allowing for an exploration of the intervention. We will present the results of a thematic analysis of interviews and field notes.

\section{Methods}

Setting

The project took place in an inner-city, high-density housing estate in the UK, with approximately 500 apartments. According to the 2001 U.K. Census, approximately $60 \%$ of residents were White and $40 \%$ from Black and ethnic minority groups. The area fell within the 14\% most deprived similar-sized areas in England (Office for National Statistics, 2007). The last author $(\mathrm{CH})$ was initially a volunteer on an intergenerational project (Alcock et al., 2011) and later employed by the youth centre on the estate. The service was funded via grants from charitable foundations. Ethical approval for the research was given by the UCL research ethics committee.

\section{Participants}

The intervention was targeted at young people (aged 14-25) not otherwise engaged in services, including education, employment, training or youth services (excluding the criminal justice system) and at a high risk of offending or re-offending. The intervention was aimed at a population that was identified through informal and participatory methods (see Table 1). Young people were identified by local community agencies as gang-affiliated through a relevant multi-agency panel and through informal assessments (for instance young people would inform us of their risk). Mental health problems were not a specific inclusion criterion for participation, but through participation in the intervention we informally assessed young people's needs.

Young people were able to self-refer by attending activities and often brought their peers along with them, which was actively encouraged. During this phase of the development, approximately 25 young people attended the project over the course of the two years. 
However, the intervention focused on a core group of 15 young people who were informally identified as the most in need in terms of the above criteria. Of the core group, the majority were male $(n=13)$ and there were two females. Most were of White British ethnicity, with a minority of Eastern European origin, Asian or Black British. This pattern of ethnicity approximated that of the local community. Median participant age was 19; range 16-22. Exact demographic data were not known for all young people because they reported that such data collection was a barrier to attendance.

\section{Music and Change: Co-production of the Intervention}

The intervention's development, which lasted for approximately two years, can be conceptualised using the community psychology theory-praxis approach outlined in Kagan et al. (2011) which refers to five broadly sequential phases. Table 1 outlines how these phases were implemented in the development of this intervention.

Insert Table 1 about here

The project activities were developed in partnership with the young people, who named the project Music \& Change $(M \& C)$. The last author, a clinical psychologist, plus an occupational therapist and a number of volunteers, including the first author, who was at the time a trainee clinical psychologist, staffed the project. As led by young people, it became centred on using contemporary music skills (e.g. DJing and lyric writing) as a vehicle for building relationships and over time helping the young people in ways they requested, including supporting their mental health. For example, practitioners worked with young people to facilitate a workshop on 'making it in the music industry' which included discussions about confidence, cannabis and relationship building. Clinical staff drew on a range of clinical models, according to the evidence-base for what topic they were discussing, for instance, drawing on motivational interviewing for exploring cannabis use. Staff also supported young people with a range of occupational and social needs as led by the young people, other professionals (e.g. a housing advisor) were invited to attend sessions to support this where required. This included benefits applications, passport applications, housing applications and employment

support. Further details of the intervention are available in Zlotowitz (2010).

\section{Formative evaluation}

Focused ethnography is designed to investigate an aspect of how a specific organisation operates (Savage 2006; Simonds et al., 2012). In the present study, we examined young people's reactions to, and experiences of, the intervention as it was under development. Data consisted of field notes, interviews and conversations with young people, stakeholders and staff, principally collected by the first and last authors, although some of the young people participated in the role of 'research consultants'. These data were analysed using thematic analysis to identify key principles (Braun \& Clarke, 2006). The analysis was conducted by the first author and audited by the second author. Guidelines for good practice in qualitative research (Stiles, 1999) were followed, such as grounding themes in the data and analytic auditing. All names were anonymised.

Results

The themes derived from the field notes and interviews are presented as principles, focusing on those pertaining to the young people's views of the quality and effectiveness of the M\&C project. They principles are: (1) Trusted relationships, (2) Responsive, flexible, and relevant, (3) Local and safe, (4) Peer- and youth-led, (5), Holistic, and (6) Creating contextual change. 


\section{Trusted Relationships}

Young people were clear that long term and consistent relationships with practitioners who seem to genuinely care, were non-judgemental and whom they trusted were core to engagement. Once these practitioners were trusted and known, young people shared their emotional experiences, looking for support.

Quote from YP6 interview: 'I've known Lisa for over a year now and l'd prefer to speak to her if I've got any problems than go to someone I don't know in some weird building...'

\section{Responsive, Flexible and Relevant}

Young people wanted provision of youth-led activities that they chose to engage with, rather than appointments they wouldn't attend because of stigma, risk of being seen as 'snitches' by other gang members and mistrust of professionals.

Quote from last author field note: 'and [YP7] told me that if you said that you want to help or support them they would all be like "Don't want that, that's a waste of time."'

Similarly, young people responded when mental health was perceived as relevant to them; for instance, how the practitioner can help them get and keep a job.

Quote from last author field note: [YP1] was really up for it and asked if we could teach him 'how to manage my anger and I will teach you how to set up the decks'. So I thought that it was a brilliant kind of way of looking at it.'

\section{Local and Safe}

Importantly, they needed these youth-led activities to be very local, within their 'safe territory', and the practitioners to come to them there and create opportunities from there.

Quote from last author field note: [YP2] tells us we have to be careful about where we put the posters [promoting the project], we can't put them in other areas because it will cause trouble [with young people from those areas].'

4. Peer- and Youth-Led

Young people were clear that word of mouth is the strongest referral system and so they would bring the 'right group' of friends along if practitioners proved themselves useful. Creating change within the peer group was valued; the activities being led by the young people themselves was central.

Quote from YP2 interview: 'Well basically, hopefully this is-I had like a little idea like to, just get more of the kids involved and then along the line. like along a couple of sessions just start with lyric writing...'

\section{Holistic support}

Over time, during sessions young people sought support for stability, jobs and their socioeconomic improvement and they sought support for these issues from practitioners before emotional support. They wanted resources, opportunities and contacts to move away from illegitimate and risky contexts into safer ones.

Quote from first author field note: 'Lisa and Jane talked to one of the young people about the possibility of her running a shop from the youth centre.'

\section{Creating Contextual Change}

Young people noted that if they did change then often the community and agencies around them did not change, leading to a sense of hopelessness and low motivation. So they wanted changes in the services around them, such as being more flexible, and their environment and opportunities to be improved. Practitioners encouraged reflections about the community around them.

Quote from first author field note: 'YYP3] said 'they [the community] hate us when we're not doing crime and when we are. Everyone can fuck off'. Others agreed.' 
Discussion

Sequential and dynamic coproduction led to development and implementation of M\&C over a two year period. Ethnographic data gave rise to a number of core principles that appeared to be key in the development of M\&C and engagement of excluded young people. These included the processes and circumstances through which young people gave help to, and sought help from, mental health practitioners.

Most notably, young people asked for and responded to youth-led activities (music) provided for members of their peer group at a local youth centre that was accessible and known to them. Practitioners were required to just 'hang out' with young people at a slow pace and in their local community spaces, which seemed to overcome the barriers of geographical safety and territory. Help-seeking changed over time, firstly by young people asking practitioners to provide occupational and/or social care support and this was provided flexibly and 'wrapped around' the activities. For example, young people would meet with practitioners before, during or after the music sessions. As time progressed, young people met the practitioners on their own outside of the music sessions. By itself this social care support was valued and seems a core part of improving the social determinants of mental health and well-being (Viner, 2012). However, young people also became more willing to explore their individual emotional experience more deeply over time once relationships with practitioners grew. This was particularly the case if exploring their mental health was felt to be relevant to their occupational and financial goals (e.g., being employed in the music industry).

The importance of building trusted relationships seemed key to young people's help-seeking and fitted with the programme's mentalization-based theory and practice (Bevington \& Fuggle, 2012). This more flexible, opportunistic and responsive approach, combined with the focus on strengths and interests, seemed to help overcome psychological help-seeking barriers and is consistent with other models for working alongside excluded young people in which the emphasis is on relationship and long term holistic support (Bevington, Fuggle, Fonagy, Asen. \& Target, 2012; Lemma, 2010). Taking any opportunities (such as whilst travelling to activities) to explore young people's internal experience and build reflective and empathic capacity, whilst drawing on individual clinical formulations and practice, was later coined 'street therapy' by practitioners.

Another important principle that emerged was for the project to be peer- and youth-led, wherever possible. The appetite for young people to want to help other young people, to bring their friends along and through the project to gain experience and utilise their skills and knowledge once they trusted the project was something practitioners learnt and harnessed quickly. Young people engaged in and valued having volunteer and employed leadership roles within the project (e.g. Head of Music) and having control of their own and their peers' inclusion in the sessions, resisting professional referrals or requirements. This seemed to help keep them safe in terms of gang affiliations and allowed them to feel more ownership and, as we hypothesised, perhaps gain self-efficacy and potentially prevent future anti-social behaviour (Weissberg, Kumpfer \& Seligman, 2003). It also seemed to create the space for young people to engage with the project in a non-stigmatising way, bringing credibility and the 'permission' and support of each other.

The phenomenon of peer referrals and trust brokered through word of mouth is common in detached youth work (Crimmens et al., 2010) but not formal mental health services. 
Similarly, working to create change for the whole peer group fits with the US's Operation Ceasefire approach to reducing gun and gang violence (Braga et al., 2001), drawing on the idea of changing wider systems around individuals that might be influencing their well-being and health behaviours (e.g., Evans \& Prilleltensky, 2007).

Young people expressed frustration about local services and community resources. This made it difficult for practitioners to engage young people with those other agencies. Practitioners tried to support young people to reflect on how such services and systems might adapt to respond to their needs and how young people could become agents of change in this process. However, this was not easy and it was difficult to assess changes to wider systems from these data.

Overall these data are consistent with the conclusions of other reviews: that young people in the criminal justice system respond most effectively to non-stigmatizing services that draw on their expertise, involve them in decision-making, offer diverse opportunities for success and the development of positive self-image, build on their strengths and address many aspects of their lives simultaneously, including the opportunity to take up therapy (Hodgkinson et al., 2009; Pitts, 2008).

\section{Limitations}

Applied ethnography was chosen as an appropriate approach, given the evaluation constraints at this stage. Even so, comparative to a full ethnographic piece of research (e.g. MacDonald \& Marsh, 2005), this research was short term and restricted in scope. In addition, as participant-observers, it is likely that we were biased by our investment in the project, although we tried to be aware of and limit this potential bias. In terms of community psychology principles, this research was not co-led with young people and therefore fell between a standard evaluation model, involving pre and post quantitative measures, and participatory action research, a preferred methodology for community psychology interventions (Kagan et al., 2013).

\section{Future Directions}

The Music \& Change project appeared to be valued by the young people, and the approach of their helping shape and co-produce it seemed key to this. This co-production, practicebased learning approach influenced the development of a model of a replicable intervention that we subsequently labelled the 'Integrate model'. This model incorporated the principles that appeared effective from these data such as 1) co-production, 2) flexibility and responsivity to local need and preferences, 3) peer referrals, 4) taking mental health practitioners out of clinics to where young people are, 5) creating change across multiple levels, 6) wrapping mental health thinking and practice around youth-led activities and 7) the importance of long term trusted and attuned relationships supporting holistic needs. From these, a phased intervention was extrapolated (similar to the approach in Table 1) and is being implemented by three pilot projects involving multiple agencies working in partnerships as providers, such as staff from local authorities and NHS Mental Health Trusts. (Details of the phases of the Integrate model are available online as supplementary document.) The challenges of clinical and operational governance and risk management within a multiagency implementation of this approach are being addressed through these pilots and further learning captured. 
A phase 2 trial, using a mixed-methods pre- and post-intervention design, is currently being conducted across these implementations of the Integrate model. We have further worked alongside young people to learn how to approach the issue of evaluation and measurement. The impact of the project on outcomes for young people and wider systems is being evaluated, with support from young people. Reports with more comprehensive data, both qualitative and quantitative, are currently under preparation and explain the learning of how we have tried to balance the needs of the service evaluation, as demanded by wider policy and the MRC guidelines, with the principles of community-led research.

\section{Acknowledgements}

Funding: MAC-UK and its activities during this period were generously funded by Comic Relief, The Paul Hamlyn Foundation, Star Lizard Ltd, Camden Council and The Tudor Trust. University College London and Camden \& Islington NHS Foundation Trust supported the funding of the research by the first author.

Conflicts of Interest: The authors have declared that they have no competing or potential conflicts of interest.

Contributorships: We would like to thank all the incredible young people who have supported the development of Music \& Change and the activities of MAC-UK. We would also like to thank the staff and volunteers of MAC-UK who continue to develop and implement the Integrate approach across MAC-UK projects with passion and dedication. Thank you also to our multi-agency partners and individuals who have supported Music \& Change and MACUK in countless ways. We would also like to thank our anonymous reviewers and the editorial team of $\mathrm{CAMH}$ who have been a huge support in improving this manuscript.

\section{References}

Alcock, C., Camic, P.M., Barker, C., Haridi, C. \& Raven, R. (2011). Intergenerational practice in the community: An applied ethnographic evaluation. Journal of Community and Applied Social Psychology, 21, 419-432.

Barrett, B., Byford, S., Chitsabesan, P. \& Kenning, C. (2006). Mental health provision for young offenders: service use and cost. British Journal of Psychiatry, 188, 541-546.

Berelowitz, S. Office of the Children's Commissioner. (2011). I think I must have been born bad: emotional wellbeing and mental health of children and young people in the youth justice system. Retrieved from:

http://www.childrenscommissioner.gov.uk/force download.php?fp=\%2Fclient assets \%2Fcp\%2Fpublication\%2F503\%2FI think I must have been born bad full report.pdf

Bevington, D., \& Fuggle, P. (2012). Supporting and enhancing mentalization in community outreach teams working with socially excluded youth: the AMBIT approach. In N. Midgley, \& I. Vrouva (Eds.) Minding the Child: mentalization-based interventions with children, young people and their families. London: Routledge.

Bevington, D., Fuggle, P., Fonagy, P., Asen, E., \& Target, M. (2012). Adolescent Mentalization-Based Integrative Therapy (AMBIT): A new integrated approach to working with the most hard to reach adolescents with severe complex mental health needs. Child and Adolescent Mental Health. 18, 46-51.

Boxer, P. (2011). Negative peer involvement in multisystemic therapy for the treatment of youth problem behavior: Exploring outcome and process variables in "real-world" practice. Journal of Clinical Child \& Adolescent Psychology, 40, 848-854. 
Braga, A. A., Kennedy, D. M., Piehl, A. M., \& Waring, E. J. (2001). Reducing gun violence: The Boston gun project's operation ceasefire. Washington, DC: National Institute of Justice.

Braun, V. and Clarke, V. (2006) Using thematic analysis in psychology. Qualitative Research in Psychology, 3(2), 77-101.

Campbell, N. C., Murray, E., Darbyshire, J., Emery, J., Farmer, A., Griffiths, F. ..., \& Kinmonth, A. L. (2007). Designing and evaluating complex interventions to improve health care. British Medical Journal, 33, 455-459.

Catch 22 \& MHP Health (2013). Violence prevention, health promotion: A public health approach to tackling youth violence. Retrieved from: http://www.catch-22.org.uk/wpcontent/uploads/2013/11/Catch22-Dawes-Unit-Violence-prevention-healthpromotion-October-2013.pdf

Chitsabesan, P., Kroll, L., Bailey, S., Kenning, C., Sneider, S., MacDonald, W., \& Theodosiou, L. (2006). Mental health needs of young offenders in custody and in the community. British Journal of Psychiatry. 188, 534-40.

Centre for Social Justice. (2009). Dying to belong: An in-depth review of street gangs in Britain. A Policy Report by the Gangs Working Group.

Coid, J. W., Ullrich, S., Keers, R., Bebbington, P., DeStavola, B. L., Kallis, C., \& Donnelly, P. (2013). Gang membership, violence, and psychiatric morbidity. American Journal of Psychiatry, 170(9), 985-993.

Craig, P., Dieppe, P., Macintyre, P., Michie, S. Nazareth, I., \& Petticrew, M. (2008). Developing and evaluating complex interventions: the new Medical Research Council guidance. 337:a1655.

Crimmens, D., Factor, F., Jeffs, T., Pitts, J., Pugh, C., Spence, J., \& Turner, P. (2004). Reaching socially excluded young people: a national study of street-based youth work. Retrieved from: http://dro.dur.ac.uk/6409/1/6409.pdf

Densley, J. (2011). Ganging up on gangs: Why the gangs intervention industry needs an intervention. The British Journal of Forensic Practice, 13, (1), 12-23.

Department of Health, U.K. Government (2009). Healthy children, safer communities. A strategy to promote the health and well-being of children and young people in contact with the youth justice system. Retrieved from:

http://www.dh.gov.uk/prod consum dh/groups/dh digitalassets/documents/digitalass et/dh 109772.pdf

Evans, S.D., and Prilleltensky, I. (2007). Youth and democracy: participation for personal, relational, and collective well-being. Journal of Community Psychology, 35, 681-692.

Fisher, H., Gardner, F., \& Montgomery, P. (2008). Cognitive-behavioural interventions for preventing youth gang involvement for children and young people (7-16). Cochrane Database of Systematic Reviews, 2.

Foot, J. \& Hopkins, T. (2010). A glass half full: how an asset approach can improve community health and well-being. IDEA Healthy Communities.

Gilman, A.B., Hill, K.G., \& Hawkins, J.D. (2014). Long-term consequences of adolescent gang membership for adult functioning. American Journal of Public Health: 104, (5), 938-945.

Goldson, B. \& Jamieson, J. (2002). Youth crime, the 'parenting deficit' and state intervention: a contextual critique. Youth Justice. 2(2), 82-99.

Hallsworth, S., \& Young, T. (2008). Gang talk and gang talkers: a critique. Crime Media and Culture, 4(2), 175-195. 
Hodgkinson, J., Marshall, S., Berry, G., Newman, M., Reynolds, P., Burton, E., Dickson, K., Anderson, J. (2009). Reducing gang related crime: A systematic review of 'comprehensive' interventions. Technical report. In: Research Evidence in Education Library. London: EPPI-Centre, Social Science Research Unit, Institute of Education, University of London.

Home Office, H.M. Government (2011). Ending gang and youth violence: a crossgovernment report including further evidence and good practice case studies. Retrieved from: http://www.homeoffice.gov.uk/publications/crime/ending-gangviolence/gang-violence-detailreport?view=Binary

Kagan, C.M., Burton, M., Duckett, P.S., Lawthom, R., \& Siddiquee, A. (2011). Critical community psychology. Oxford: Wiley-Blackwell.

Kintrea, K., Banister, J., Reid, M., and Suzuki, N. (2008). Young people and territoriality in British cities. York: Joseph Rowntree Foundation.

Kelly, S. (2010). The psychological consequences to adolescents of exposure to gang violence in the community: an integrated review of the literature. Journal of Child and Adolescent Psychiatric Nursing, 23(2), 61-73.

Khan, L. Brice, H. Saunders, A., \& Plumtree, A. (2013). A need to belong. What leads girls to join gangs? Centre for Mental Health.

Kurtz, K., Thornes, R. \& Bailey, S. (1998). Children in the criminal justice and secure care systems: how their mental health needs are met. Journal of Adolescence. 21, 543553.

Lemma, A. (2010). The power of relationship: A study of key working as an intervention with traumatised young people. Journal of Social Work Practice, 24(2), 409-427.

MacDonald, R., \& Marsh, J. (2005). Disconnected youth? Growing up in Britain's poor neighbourhoods. Palgrave Macmillan.

McMahon, S. (2013). Gangs, youth violence \& gangs. Project Oracle. Children \& youth evidence hub. Retrieved from:

http://projectoracle.com/uploads/files/Project Oracle Synthesis Study 03-

2013 Gangs and youth violence.pdf

National Institute for Health and Care Excellence. (2008). Community engagement. NICE public health guidance 9. London: National Institute for Health and Care Excellence.

National Institute for Health and Care Excellence. (2013). Antisocial behaviour and Conduct Disorders in children and young people: recognition, intervention and management. NICE clinical guideline 158. London: National Institute for Health and Care Excellence.

North West Public Health Observatory. (2012). Protecting people: Promoting health -- $A$ public health approach to violence prevention for England. Retrieved from https://www.gov.uk/government/publications/a-public-health-approach-to-violenceprevention-in-england

Oetzel, K., \& Scherer, D.G. (2003). Therapeutic engagement with adolescents in psychotherapy. Psychotherapy: Theory, Research, Practice, Training, 40(3), 215225.

Pitts, J. (2004). So what does work? Safer Communities, 3, (4), $24-36$.

Pitts, J. (2008). Reluctant gangsters: the changing face of youth crime, Cullompton: Willan Publishing.

Quigley, R. (2004). Positive peer groups: "helping others" meets primary developmental needs. Reclaiming Children and Youth, 13, 134-137. 
Savage, J. (2006). Ethnographic evidence: The value of applied ethnography in healthcare. Journal of Research in Nursing, 11(5), 383-393.

Simonds, L.M., Camic, P.M., \& Causey, A. (2012). Using focused ethnography in psychological research. In H. Cooper (Ed.), APA handbook of research methods in psychology. Washington DC: American Psychological Association.

Slay, J., \& Stephens, L. (2013). Co-production in mental health: A literature review. New Economics Foundation, London.

Stiles, W.B. (1999). Evaluating qualitative research. Evidence Based Mental Health, 2, 99101.

Viner, R.M. (2012). Adolescence and the social determinants of health. The Lancet. 379, (9826), 1641-52.

Walsh, J., Scaife, V., Notley, C., Dodsworth, J., \& Schofield, G. (2011). Perception of need and barriers to access: the mental health needs of young people attending a Youth Offending Team in the UK. Health Social Care in the Community. 19, (4), 420-8.

Weissberg, R., Kumpfer, K.L. and Seligman, M.E. (2003). Prevention that works for children and youth: An introduction. American Psychologist, 58, 425-432.

Wood, J., \& Alleyne, E. (2010). Street gang theory and research: Where are we now and where do we go from here? Aggression and Violent Behavior, 15, (2), 100-111.

Youth Justice Board. (2005). Effectiveness of mental health provision for young offenders in custody and the community. London: Youth Justice Board.

Zlotowitz, S. (2010). Grime not crime: the psychological impact of a community-based music project for marginalized young people. Unpublished doctoral thesis, University College London, London, UK. 
Table 1: Overview of the Intervention's Development

Phase Operationalization

1. Making contact and gaining entry into the community

2. Stakeholder analysis, community mapping and partnership building

3. Action and Implementation pilot project and 'Capacitation'

4. Evaluation

5. Cycle of ongoing implementation, development with cohorts of young people and evaluation.
The last author $(\mathrm{CH})$ made contact with the relevant target group of young people through 'hanging out' where young people gathered (e.g. the local fish and chip shop). She also built a relationship with a well-liked youth worker from the centre who acted as a community gatekeeper (see Sixsmith, Boneham \& Goldring, 2003).

As part of her role in the youth centre, $\mathrm{CH}$ attended Local Authority multi-agency panel meetings discussing young people within the Borough involved in anti-social behaviour and gangs. This and other relationships with community members allowed her to map both relevant stakeholders (e.g. the police) and those young people least engaged with these stakeholders' services and to build partnerships with these stakeholders.

By request of the young people, $\mathrm{CH}$ with support of partners, a volunteer and gatekeepers began music-based and employment support activities (e.g. DJ and music production sessions) on a twice -weekly basis in the youth centre. See 'Intervention' section.

Using applied ethnographic methods, the study identified the key features of the project that the young people identified as important and created psychological change (Zlotowitz, 2010).

See 'Future Directions' section. 


\section{Appendix 1 - Phases of the 'Integrate Model'}

1) 'Hanging Out - spending time in the community where young people are, making initial contact with them, finding community gatekeepers who can facilitate access to the target group.

2) Asking for Help - genuinely asking help for young people to create activities of interest and importance to them and offering resources to achieve this; ongoing outreach and peer referrals. Employing young people in the project to support the development of these youth-led activities.

3) Building Relationships - practitioners building long-term trusted relationships with young people by participating in youth-led activities and projects, such as music, sport or eating food together for the length of the project.

4) 'Street therapy' - practitioners creating and sharing clinical formulations of young people and providing clinical interventions during everyday interactions with young people, e.g. on the bus on the way to court. Clinicians draw on evidence-based practice.

5) 'Bridging Out and Building Bridges' - proactively creating partnerships with local organisations and services to 'bridge' young people into, in order to sustainably meet their needs, from welfare support, employment to mainstream health services, as appropriate.

6) Changing wider systems - proactively supporting young people alongside practitioners to become social change agents to address the wider local community and systems, such as the police or housing services, through training, social policy work, social action, consultation, research or any other means.

Paper in press, Child and Adolescent Mental Health

Pre-publication draft. Please do not quote without permission.

Version dated: 8 September 2015

Please address correspondence to:

Chris Barker c.barker@ucl.ac.uk

Research Department of Clinical, Educational and Health Psychology

University College London

Gower Street

London WC1E 6BT 